Check for updates

Cite this: RSC Adv., 2018, 8, 33301

Received 13th July 2018

Accepted 15th September 2018

DOI: $10.1039 / c 8 r a 05968 c$

rsc.li/rsc-advances

\section{Comparative study on synchronous adsorption of arsenate and fluoride in aqueous solution onto MgAlFe-LDHs with different intercalating anions $\dagger$}

\author{
Lu Hongtao, ab Liu Shuxia, ${ }^{a}$ Zhang Hua, ${ }^{a}$ Qiu Yanling, ${ }^{c}$ Yin Daqiang, ${ }^{c}$ Zhao Jianfu ${ }^{a}$ \\ and Zhu Zhiliang (D) *ac
}

In this study, a series of $\mathrm{MgAlFe}-\mathrm{LDHs}\left(\mathrm{Cl}^{-}, \mathrm{NO}_{3}{ }^{-}\right.$, intercalation, and calcined products of a $\mathrm{CO}_{3}{ }^{2-}$ interlayer) was synthesized and used for adsorption of arsenate and fluoride in individual contaminants and coexisting pollutant systems. Effects of various factors such as initial $\mathrm{pH}$ of solution, dosage of materials, coexisting ions, contact time, and initial pollutant concentrations were evaluated. Experimental results showed that different intercalating anions had a significant effect on adsorption performance of arsenate and fluoride in water. The adsorption of arsenate and fluoride on MgAlFe-CLDH, MgAlFe-Cl- $\mathrm{LDH}$ or $\mathrm{MgAlFe}-\mathrm{NO}_{3}-$ $\mathrm{LDH}$ can be described by different adsorption isotherm equations. During the simultaneous removal process, arsenate and fluoride competed for adsorption sites of the adsorbent materials, and the fluoride ions had advantages in the competitive adsorption on MgAlFe-Cl-LDH and MgAlFe- $\mathrm{NO}_{3}-\mathrm{LDH}$. MgAlFe$\mathrm{NO}_{3}-\mathrm{LDH}$ was used to adsorb arsenate and fluoride in coexisting pollution systems (the concentration of each pollutant was $2 \mathrm{mg} \mathrm{L}^{-1}$, the adsorbent dosage was $1.5 \mathrm{~g} \mathrm{~L}^{-1}$ ). The remaining arsenic concentration was reduced to less than $10 \mu \mathrm{g} \mathrm{L}^{-1}$ and the remaining fluoride ion concentration to below $20 \mu \mathrm{g} \mathrm{L}^{-1}$ which meets the World Health Organization's, EPA's and China's drinking water standards for arsenic and fluoride limits. A possible mechanism is discussed with support from further XRD, SEM, and XPS analysis of the materials after their adsorption.

\section{Introduction}

Arsenic and fluoride are contaminants present in natural water environments, and often coexist in groundwater. Especially in some countries, such as China, ${ }^{1}$ Mexico, ${ }^{2}$ Pakistan, ${ }^{3,4}$ Afghanistan, ${ }^{5}$ India, ${ }^{6}$ Argentina, and Chile, ${ }^{7}$ concentrations of arsenic and fluoride in groundwater in some areas are much higher than WHO's and local drinking water standards. Arsenic and fluoride have harmful effects on human health and there are many toxicological studies on arsenic and fluoride coexisting systems..$^{8-10}$ Some research results have shown that when arsenic and fluoride coexist in water, due to the interaction between them, they will further exacerbate human body neurotoxicity. ${ }^{\mathbf{1 1}}$

${ }^{a}$ State Key Laboratory of Pollution Control and Resource Reuse, Tongji University, Shanghai 200092, China

${ }^{b}$ Postdoctoral Research Station, College of Civil Engineering, Tongji University, Shanghai 200092, China

${ }^{c}$ Key Laboratory of Yangtze River Water Environment, Ministry of Education, Tongji University, Shanghai 200092, China. E-mail: zzl@tongii.edu.cn; Fax: +86-21-6598 4626; Tel: +86-21-6598 2426

$\dagger$ Electronic supplementary information (ESI) available: Full-range XPS spectra of materials, effect of dosage on arsenic and fluoride adsorption, effect of $\mathrm{pH}$ on arsenic and fluoride adsorption, SEM image and EDS figure of material after adsorption of arsenic and fluoride. See DOI: 10.1039/c8ra05968c
In recent years, the control of pollution resulting from arsenic and fluoride gradually has aroused people's attention. ${ }^{\mathbf{1 2}}$ Research on the removal of arsenic and fluoride mainly focused on coagulation, ${ }^{13}$ adsorption, ${ }^{14,15}$ filtration, ${ }^{16,17}$ and phytoremediation. ${ }^{18,19}$ It is known that one of the most promising methods for simultaneous removal of arsenic and fluoride is adsorption because of its low-cost and convenience. Recently, many adsorbents have been used to remove arsenic and fluoride simultaneously, such as granular $\mathrm{TiO}_{2}-\mathrm{La}$ material, ${ }^{15}$ aluminum oxide/hydroxide nanoparticles, ${ }^{20}$ iron oxide nano particles, ${ }^{\mathbf{1 4}}$ chemically treated laterite, ${ }^{21}$ brick pieces and marble powder, ${ }^{22}$ activated red mud, ${ }^{23}$ and layered double hydroxide. ${ }^{24,25}$

Layered double hydroxides (LDHs) may be suitable adsorbents for the treatment of arsenic and fluoride complexes pollution in water. Compared to other synthetic adsorbents, the synthesis process of LDHs is relatively simple and less costly. The general formula of LDHs as a layered structure anionic clay is $\left[\mathrm{M}^{\mathrm{II}}{ }_{1-x} \mathrm{M}_{x}{ }^{\mathrm{III}}(\mathrm{OH})_{2}\right]^{x+}\left(\mathrm{A}^{n-}\right)_{x / n} \cdot m \mathrm{H}_{2} \mathrm{O}$, where $\mathrm{M}^{\mathrm{II}}$ and $\mathrm{M}^{\mathrm{III}}$ are divalent and trivalent cations, respectively while $\mathrm{A}^{n-}$ denotes an interlayer anion; LDHs have found wide application in the field of pollutant removal in water. ${ }^{26,27}$ In particular, LDHs have been used to adsorb arsenic or fluoride in single pollutant systems, ${ }^{28}$ and several LDHs with high adsorption capacity for arsenic or fluoride in water have been reported. ${ }^{29-35}$ Simultaneous removal of arsenic and fluoride in water is very important for the 
protection of human health and ecosystems. However, adsorbents with high adsorption capacity for removal of individual contaminants are not necessarily suitable for simultaneous removal of arsenic and fluoride. ${ }^{12}$ Studies have shown that the simultaneous adsorption of arsenic and fluorine is more efficient with $\mathrm{CLDH}$ (calcined product of LDHs). ${ }^{25,36}$ The fact that the structure of $\mathrm{CLDH}$ is prone to structural rebuilding makes the material more recyclable. It also means that arsenic and fluorine are not completely fixed on the material. Application of adsorbents has been hindered due to the influence of other ions in actual water environments and stability after adsorption of pollutants. ${ }^{12}$ Similarly, limited knowledge is available about comparative adsorption of arsenic and fluoride on LDHs during the simultaneous removal process. A study of the competitive adsorption processes, coexisting ions effect, and possible release after adsorption can facilitate the design of adsorbents for practical application.

Based on our previous research on $\mathrm{LDHs},{ }^{37-40}$ the objective of this study is to investigate the effect of different intercalation anions on the simultaneous removal of arsenic and fluoride on MgAlFe-LDHs materials in water. Thus, a series of LDHs with different anion intercalation layers were synthesized and the adsorption of arsenate and fluoride on these materials was studied. Effects of various factors in the adsorption process such as initial pH of solution, dosage of materials, coexisting ions, contact time, and initial pollutant concentration were evaluated. A possible mechanism of adsorption and release of arsenic and fluorine after adsorption are discussed. The results may be helpful for the treatment of arsenic and fluoride contaminated water and be beneficial for further understanding the competitive adsorption behavior of arsenate and fluoride on LDHs materials.

\section{Materials and methods}

\section{Chemicals}

Sodium fluoride and all chemicals used for synthesis were analytical grade and purchased from Sinopharm Group Reagent Co., Ltd. The arsenate $\left(\mathrm{Na}_{2} \mathrm{HAsO}_{4} \cdot 7 \mathrm{H}_{2} \mathrm{O}\right)$ was purchased from Sigma-Aldrich with a purity higher than $98 \%$. Stock solutions of $1000 \mathrm{mg} \mathrm{L}^{-1} \mathrm{As}(\mathrm{v})$ and $\mathrm{F}^{-}$were prepared with Milli-Q water (18.2 $\mathrm{M} \Omega \mathrm{cm}$ at $25{ }^{\circ} \mathrm{C}$ ), respectively. Then, working solutions were obtained by diluting the stock solutions with de-ionized water.

\section{Synthesis of LDHs}

$\mathrm{Mg}-\mathrm{Al}-\mathrm{Fe}-\mathrm{LDH}$ with a nitrate interlayer were synthesized by a co-precipitation method. First, $0.05 \mathrm{~mol} \mathrm{Mg}\left(\mathrm{NO}_{3}\right)_{2} \cdot 6 \mathrm{H}_{2} \mathrm{O}$, $0.045 \mathrm{~mol} \mathrm{Al}\left(\mathrm{NO}_{3}\right)_{3} \cdot 9 \mathrm{H}_{2} \mathrm{O}$, and $0.005 \mathrm{~mol} \mathrm{Fe}\left(\mathrm{NO}_{3}\right)_{3} \cdot 9 \mathrm{H}_{2} \mathrm{O}$ were dissolved in $100 \mathrm{~mL}$ of deionized water to obtain a metal ion mixed solution. Then, $0.1 \mathrm{~mol} \mathrm{NaNO}_{3}$ and $0.2 \mathrm{~mol}$ of $\mathrm{NaOH}$ were dissolved in $100 \mathrm{~mL}$ of deionized water to obtain an alkali solution. Next, the prepared metal ion mixed solution and the alkali solution were simultaneously dropped into a high-speed stirred reactor containing $50 \mathrm{~mL}$ of deionized water while the reactor was charged with nitrogen as a protective gas. Appropriate amounts of $\mathrm{NaOH}$ or $\mathrm{HCl}$ solution were added to the reactor in order to maintain the $\mathrm{pH}$ value around 10. After the reaction was complete, the mixture was stirred for 30 minutes. The resulting suspension was placed in an oven and aged for 24 hours at $353 \mathrm{~K}$. Then, centrifugal separation and washing were carried out. The precipitate was washed repeatedly with deionized water until the $\mathrm{pH}$ of the supernatant was neutral. The obtained material was then dried at $353 \mathrm{~K}$ and ground to powder and the product was named $\mathrm{MgAlFe}-\mathrm{NO}_{3}-\mathrm{LDH}$. The $\mathrm{MgAlFe}-\mathrm{Cl}-\mathrm{LDH}$ and $\mathrm{MgAlFe}-\mathrm{CO}_{3}-\mathrm{LDH}$ were also prepared by the same method by using the corresponding chloride or carbonate instead of nitrate. The $\mathrm{MgAlFe}-\mathrm{CO}_{3}-\mathrm{LDH}$ was calcined at $773 \mathrm{~K}$ in a muffle furnace for 4 hours and, after cooling, the calcined product MgAlFe-CLDH was obtained. According to the different contents of intercalated ions, the materials were named MgAlFe- $\mathrm{NO}_{3}-\mathrm{LDH}, \mathrm{MgAlFe}-\mathrm{Cl}-\mathrm{LDH}$, and MgAlFe-CLDH, respectively.

\section{Characterization and analysis}

The aqueous arsenate concentration was determined by inductively coupled plasma optical emission spectrometry (ICPOES) (720 ES, Agilent Technologies) and atomic fluorescence spectrometry (AFS) (FP6-A, PERSEE). Fluoride concentration was determined by ion chromatography (DIONEX ICS 5000, Thermo Scientific). The materials were characterized by X-ray diffractometer (XRD) (D8 Advance, Bruker), Fourier transfer infrared (FTIR) spectrophotometer (Nicolet 6700, Nicolet), specific surface area analyzer (Autosorb-iQ, Quanta Chrome Instruments), and scanning electron microscopy (SEM) (CM200FEG, PHILIPS and S-4800, HITACHI). Elemental composition and the valence states on the surfaces of the materials were analyzed by X-ray photoelectron spectroscopy (XPS) (EscaLab 250Xi, Thermo Scientific).

\section{Adsorption experiments}

Batch adsorption experiments were carried out using a conical flask as an adsorption reaction vessel and placed in a constant temperature shaking incubator at $298 \mathrm{~K}$ with $150 \mathrm{rpm}$. If not specified, the dosage of materials were $0.6 \mathrm{~g} \mathrm{~L}^{-1}$, the initial $\mathrm{pH}$ was adjusted to 6.0, and the adsorption reaction lasted for 24 hours to achieve equilibrium. After reaction, the supernatants were collected and filtered with a $0.22 \mu \mathrm{m}$ needle filter before measuring the concentrations of residual arsenate and fluoride. All experiments were repeated twice.

In the isothermal experiments, the concentration range of arsenate ranged from $1 \mathrm{mg} \mathrm{L}^{-1}$ to $100 \mathrm{mg} \mathrm{L}^{-1}$. The concentration gradient of fluoride ion was from $1 \mathrm{mg} \mathrm{L}^{-1}$ to $30 \mathrm{mg} \mathrm{L}^{-1}$. The concentration ranges of arsenic and fluoride co-adsorption were consistent with the concentration range of a single pollutant system. In the kinetic and coexisting ion effects experiments, the initial concentrations of arsenic or fluoride were $5 \mathrm{mg} \mathrm{L}^{-1}$. A certain concentration of anionic sodium salt $\left(\mathrm{NaCl}, \mathrm{NaNO}_{3}, \mathrm{Na}_{2} \mathrm{CO}_{3}, \mathrm{Na}_{2} \mathrm{SO}_{4}, \mathrm{Na}_{2} \mathrm{HPO}_{4}\right)$ was added to the aqueous solution containing the contaminants to assess the effect of coexisting anions on adsorption. The initial concentrations were set at $2 \mathrm{mg} \mathrm{L}^{-1}$ in experiments of dosage effects. The $\mathrm{pH}$ of the system was adjusted to 6.0. The dosage of 
adsorbents was set from $0.2 \mathrm{~g} \mathrm{~L}^{-1}$ to $2.5 \mathrm{~g} \mathrm{~L}^{-1}$. In the evaluation of the effects of $\mathrm{pH}$ on adsorption of arsenic, the initial arsenic concentration was $10 \mathrm{mg} \mathrm{L}^{-1}$, and the initial concentration of fluoride was $5 \mathrm{mg} \mathrm{L}{ }^{-1}$ when assessing the effect of adsorbed fluoride. The $\mathrm{pH}$ range was from 3.0 to 10.0 .

\section{Desorption experiments}

Adsorbents with a dosage of $0.4 \mathrm{~g}$ were added to a $50 \mathrm{~mL}$ solution where the initial concentration of arsenate or fluoride $\left(C_{0}\right)$ was $10 \mathrm{mg} \mathrm{L}^{-1}$. After the adsorption had equilibrated (298 $\mathrm{K}, 150 \mathrm{rpm}, 24 \mathrm{~h}$ ), the supernatant was taken and used to determine the concentrations of the remaining arsenate and fluoride, and the solid was obtained by centrifugation. Deionized water, $\mathrm{NaOH}, \mathrm{Na}_{2} \mathrm{CO}_{3}$, and $\mathrm{Na}_{2} \mathrm{HPO}_{4}$ solutions were used as the eluent, respectively. Conditions of the desorption test were set as that of the concentration of eluent which was $500 \mathrm{mg} \mathrm{L}^{-1}$, the reaction temperature was $298 \mathrm{~K}$, the oscillation frequency was $150 \mathrm{rpm}$, and the time of desorption was 24 hours.

\section{Results and discussion}

\section{Characterization}

XRD patterns of the synthesized LDHs and the calcined material (CLDH) are shown in Fig. 1a. It can be seen from Fig. 1a that the MgAlFe-Cl-LDH and $\mathrm{MgAlFe}-\mathrm{NO}_{3}-\mathrm{LDH}$ materials show a series of characteristic diffraction peaks (003) (006) (015) (018) (110), and (113). ${ }^{41}$ Because of having been calcined at a high temperature of $778 \mathrm{k}$, crystal water, free water, lamellar hydroxyl dehydration, and $\mathrm{CO}_{3}{ }^{2-}$ had all been removed and the corresponding characteristic peaks of the lamellar structure disappeared in the CLDH materials. The diffraction peaks of MgAlFe-CLDH appearing at $2 \theta$ of $43^{\circ}$ and $63^{\circ}$ are $\mathrm{Mg}-\mathrm{O}$ and $\mathrm{Al}-\mathrm{O}$ which are characteristic peaks (JCPDES no: 30-794).

FTIR spectra of the prepared materials are shown in Fig. $1 \mathrm{~b}$. The strong and broad absorption peaks in the range of about $3450 \mathrm{~cm}^{-1}$ are derived from the stretching vibration of the hydroxyl groups of the LDHs and the water molecules in the layers, while the bending vibration absorption peaks of the water molecules are at $1639 \mathrm{~cm}^{-1}, 1384 \mathrm{~cm}^{-1}$ is $\mathrm{NO}_{3}^{-}$ antisymmetric stretching vibration, the absorption peak in the low frequency region between wave numbers $500-100 \mathrm{~cm}^{-1}$ is the metal oxygen bond and the metal hydrogen bond, ${ }^{\mathbf{4 2}}$ namely $\mathrm{Mg}-\mathrm{O}, \mathrm{Mg}-\mathrm{OH}, \mathrm{Fe}-\mathrm{O}, \mathrm{Fe}-\mathrm{OH}, \mathrm{Al}-\mathrm{O}$, and $\mathrm{Al}-\mathrm{OH}$.

The $\mathrm{N}_{2}$ adsorption/desorption isotherms of the synthesized materials are shown in Fig. 2a-c. It can be seen from the figures that the adsorption isotherms of these three materials are similar, and the adsorption and desorption curves contain H3 type hysteresis loops, ${ }^{\mathbf{4 3}}$ which conform to an IV adsorption isotherm in the IUPAC classification, indicating that the three materials are all mesoporous materials. ${ }^{44}$ It also shows that the three materials have parallel plate structures of the slit hole. At the beginning of cohesion, since the gas-liquid interface is a large plane, capillary condensation occurs only when the pressure is close to the saturated vapor pressure. The specific surface area was calculated by the multi-point BET method. The average pore size was calculated by the $\mathrm{BJH}$ method using desorption curve data (Fig. 2d). A summary of results are listed in Table 1. The calculated average pore size also shows that the three materials are mesoporous materials.

SEM images of the synthesized materials are shown in Fig. 3. It can be seen that $\mathrm{MgAlFe}-\mathrm{Cl}-\mathrm{LDH}$ and $\mathrm{MgAlFe}-\mathrm{NO}_{3}-\mathrm{LDH}$ have sheet-like morphology which shows that the materials have a layered structure. MgAlFe-CLDH has no hierarchical structure and the surface was rough due to decomposition of water and carbon dioxide during the calcination process. Composition of surface elements of the material was analyzed by XPS where it can be seen in Fig. S1-S3† that the metal ratios of MgAlFe$\mathrm{CLDH}, \mathrm{MgAlFe}-\mathrm{Cl}-\mathrm{LDH}$, and $\mathrm{MgAlFe}-\mathrm{NO}_{3}-\mathrm{LDH}$ were approximately the same.

\section{Adsorption of arsenic}

Isotherms of arsenic adsorption. In order to understand the adsorption process of arsenate in the three adsorbent materials, an isothermal adsorption experiment was carried out. Langmuir, ${ }^{45,46}$ Freundlich, ${ }^{47}$ and Sips $^{48}$ models were used to analyze the relative data obtained from the adsorption experiment for arsenic and their fitting curves are shown in Fig. 4a-c. The relevant parameters were calculated, as shown in Table S1. $\dagger$
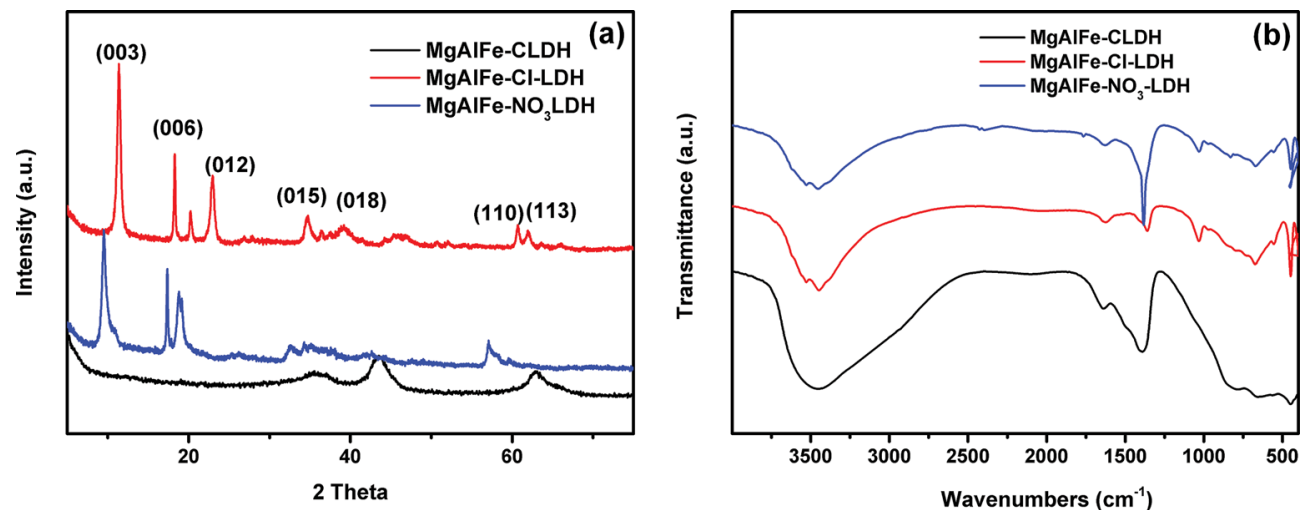

Fig. 1 (a) XRD patterns of MgAlFe-CLDH, MgAlFe-Cl-LDH, and MgAlFe-NO $-\mathrm{LDH}$. (b) FTIR spectra of MgAlFe-CLDH,MgAlFe-Cl-LDH, and $\mathrm{MgAl}-\mathrm{e}-\mathrm{NO}_{3}-\mathrm{LDH}$. 

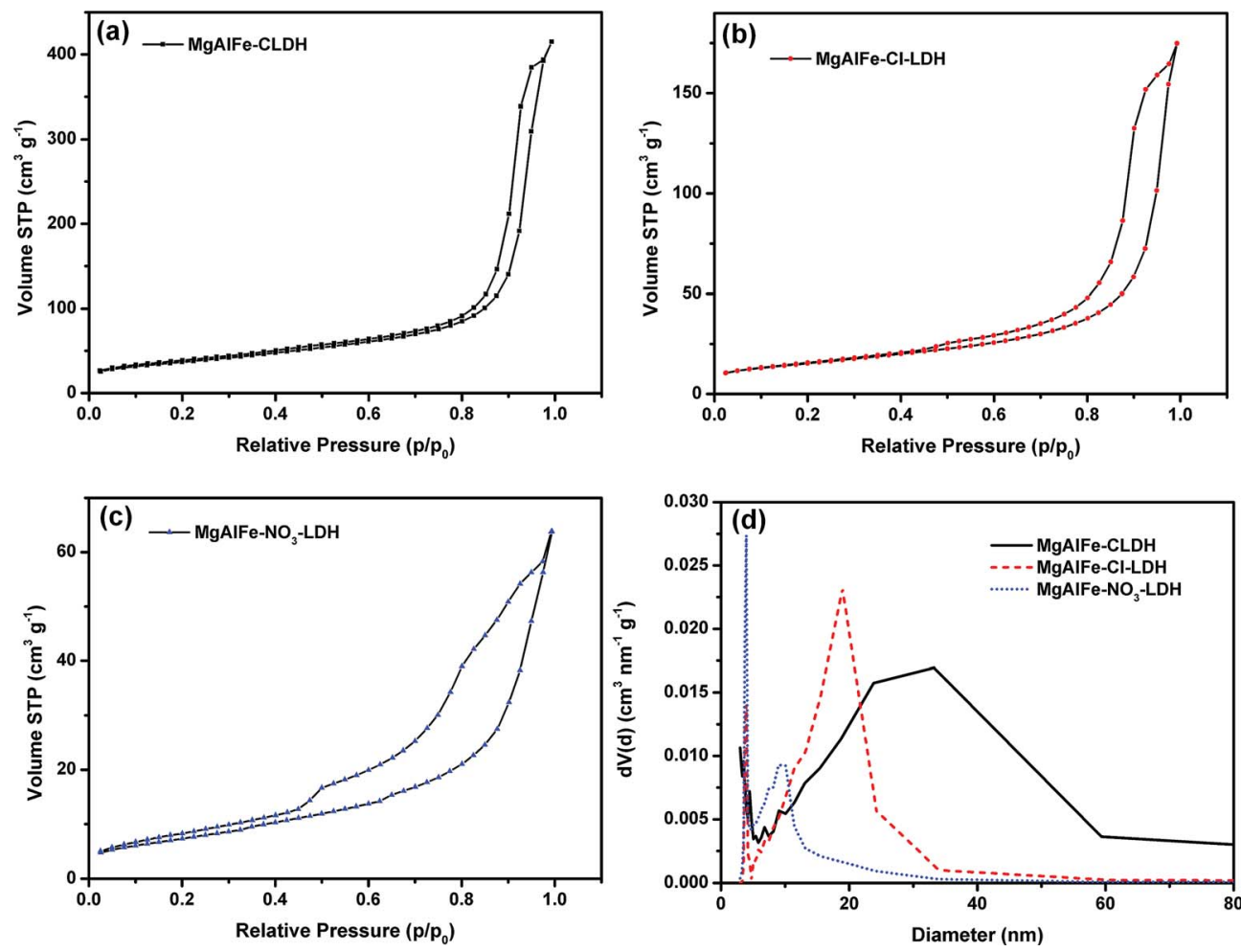

Fig. 2 (a) $\mathrm{N}_{2}$ adsorption/desorption isotherms of MgAlFe-CLDH. (b) $\mathrm{N}_{2}$ adsorption/desorption isotherms of MgAlFe-Cl-LDH. (c) $\mathrm{N}_{2}$ adsorption/ desorption isotherms of $\mathrm{MgAlFe}-\mathrm{NO}_{3}-\mathrm{LDH}$. (d) Pore size distribution of three materials (BJH method).

Table 1 Specific surface areas of the synthetic materials, average pore size, and total pore volume

\begin{tabular}{|c|c|c|c|c|}
\hline MgAlFe-CLDH & 130.39 & 197.6 & 0.6418 & 24.468 \\
\hline $\mathrm{MgAlFe}-\mathrm{NO}_{3}-\mathrm{LDH}$ & 27.38 & 53.35 & 0.0987 & 3.924 \\
\hline
\end{tabular}

The adsorption of arsenate by MgAlFe-CLDH was more consistent with the Freundlich adsorption isotherm equation in the following form:

$$
Q_{\mathrm{e}}=K_{\mathrm{F}} C_{\mathrm{e}^{\frac{1}{n}}}
$$

where $Q_{\mathrm{e}}\left(\mathrm{mg} \mathrm{g}^{-1}\right)$ is the equilibrium adsorption capacity, $K_{\mathrm{F}}(\mathrm{L}$ $\mathrm{mg}^{-1}$ ) is the Freundlich constant, and $1 / n$ is the heterogeneity factor.

The data where As(v) adsorbed onto the MgAlFe-Cl-LDH and $\mathrm{MgAlFe}-\mathrm{NO}_{3}-\mathrm{LDH}$ were more conformed to the Sips equation. The Sips isotherm model follows:

$$
Q_{\mathrm{e}}=\frac{K_{\mathrm{S}} Q_{\mathrm{m}} C_{\mathrm{e}}{ }^{m}}{1+K_{\mathrm{S}} C_{\mathrm{e}}{ }^{m}}
$$

where $C_{\mathrm{e}}\left(\mathrm{mg} \mathrm{L}^{-1}\right)$ is the equilibrium concentration, $Q_{\mathrm{m}}(\mathrm{mg}$ $\left.\mathrm{g}^{-1}\right)$ and $Q_{\mathrm{e}}\left(\mathrm{mg} \mathrm{g}^{-1}\right)$ are the maximum and equilibrium adsorption capacity, respectively, $K_{\mathrm{S}}\left(\mathrm{L} \mathrm{mg}^{-1}\right)$ is the Sips isotherm constant, and $m$ is the Sips isotherm exponent.
The Sips adsorption isothermal equation is usually seen as an improved version of the Langmuir equation. The Langmuir model follows:

$$
Q_{\mathrm{e}}=\frac{Q_{\mathrm{m}} K_{\mathrm{L}} C_{\mathrm{e}}}{1+K_{\mathrm{L}} C_{\mathrm{e}}}
$$

where $K_{\mathrm{L}}\left(\mathrm{L} \mathrm{mg}^{-1}\right)$ is the Langmuir adsorption constant.

An interesting result is that the adsorption capacity of arsenic in LDHs intercalated with nitrate is slightly higher than that of CLDH, which is different from previous reports. ${ }^{27,34,49,50} \mathrm{It}$ has been reported that nitrate between the LDHs' layers is most likely to exchange with arsenate compared to other interlayer ions. ${ }^{51}$ When the concentration of arsenate in the water is higher, then a larger extent of the inter-layer nitrate ion exchange reaction will take place. Thus, the maximum adsorption capacity fitted from the adsorption isotherm curve appears to be close to or slightly higher than that of CLDH material.

Kinetics of arsenic adsorption. The adsorption kinetics of arsenic in MgAlFe-CLDH, MgAlFe-Cl-LDH, and MgAlFe- $\mathrm{NO}_{3}$ - 


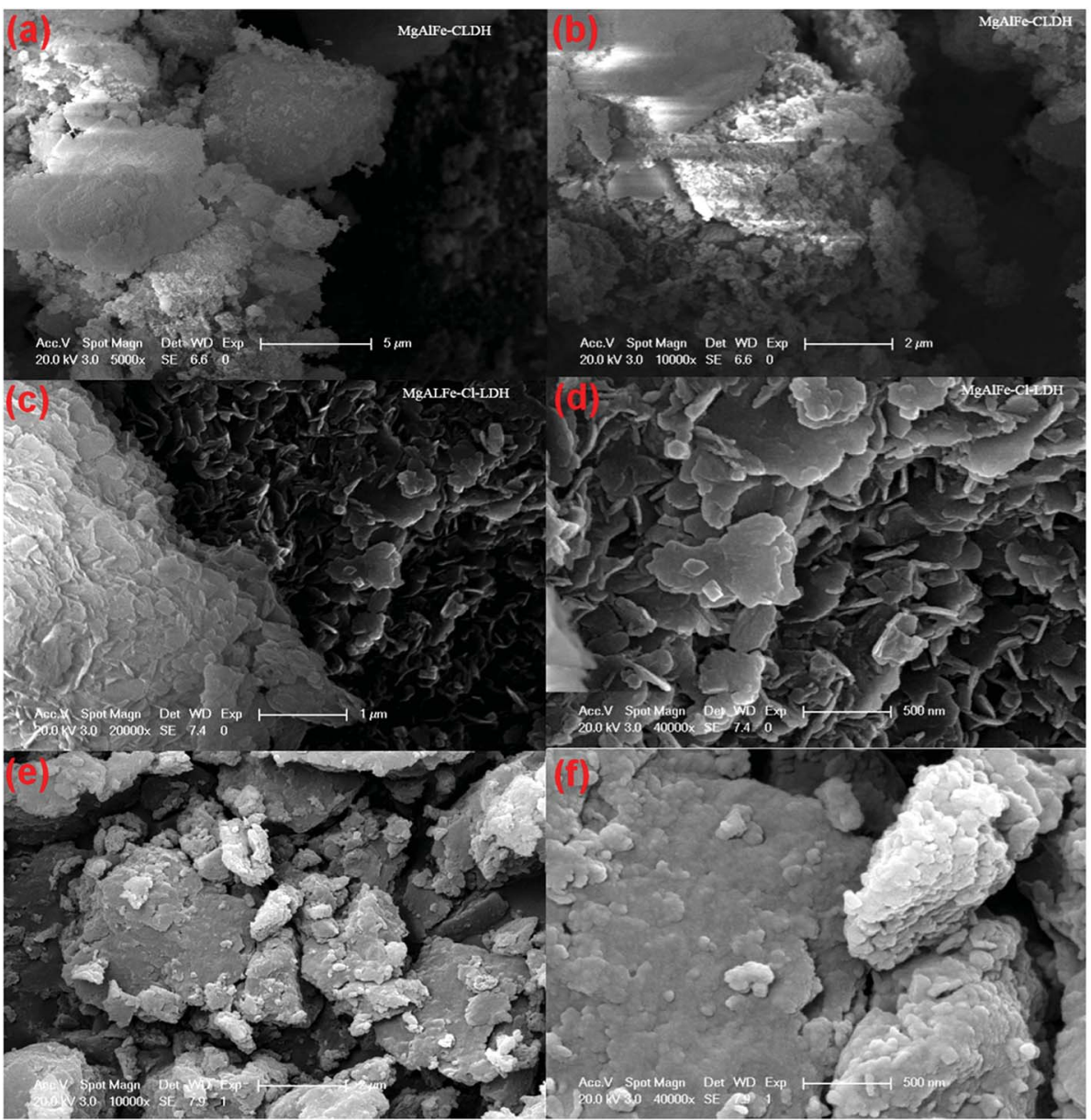

Fig. 3 SEM image of the materials (a) and (b) MgAlFe-CLDH, (c) and (d) MgAlFe-Cl-LDH, (e) and (f) MgAlFe-NO $-\mathrm{LDH}$.

LDH are shown in Fig. 4d. It is found that the arsenic adsorption rate of the materials was fast in the first 3 hours, probably because the adsorbent has more active sites in the initial stage. With the prolongation of time, the adsorption sites in the adsorbent were occupied by arsenate, the arsenate concentration in the solution was also reduced, and the reaction rate was reduced until the adsorption reached equilibrium. In order to further explore the adsorption process, a pseudo-first order kinetic model and pseudo-second order kinetic model were used to fit relevant data of the arsenate adsorption kinetics experiments. $^{52}$

The pseudo-first order kinetic model equation follows:

$$
\ln \left(Q_{\mathrm{e}}-Q_{t}\right)=\ln Q_{\mathrm{e}}-K_{1} t
$$

And the pseudo-second order kinetic model equation follows:

$$
\frac{t}{Q_{t}}=\frac{1}{K_{2} Q_{\mathrm{e}}{ }^{2}}+\frac{t}{Q_{\mathrm{e}}}
$$

where $Q_{\mathrm{e}}\left(\mathrm{mg} \mathrm{g}^{-1}\right)$ and $Q_{t}\left(\mathrm{mg} \mathrm{g}^{-1}\right)$ are adsorption amounts of the adsorbents at equilibrium and at time $t$, respectively; $K_{1}$ $\left(\mathrm{min}^{-1}\right)$ and $K_{2}\left[\mathrm{~g}(\mathrm{mg} \mathrm{min})^{-1}\right]$ are the adsorption rate constants.
As shown in Table $\mathbf{S} 2, \dagger$ correlation coefficients of the three materials with the pseudo-second order kinetic equation model are larger than those of the pseudo-first order kinetic equation. This suggests that the pseudo-second order kinetic model can better reflect the adsorption of arsenate on these materials.

Effects of anions on arsenic adsorption. There are many different kinds of substances in a natural water system, and especially the presence of various anions may affect adsorption of arsenate on a material. Therefore, we selected several common anions in water to study their effects on the adsorption of arsenic. The $\mathrm{PO}_{4}{ }^{3-}, \mathrm{SO}_{4}{ }^{2-}, \mathrm{CO}_{3}{ }^{2-}, \mathrm{NO}_{3}{ }^{-}$, and $\mathrm{Cl}^{-}$ions were selected as coexisting ion influencing factors and effects of excess anions on the adsorption of arsenate on materials were investigated. The experimental results are shown in Fig. 5. The presence of phosphate can significantly affect removal efficiency of pentavalent arsenic in water. When the concentration of phosphate in water was $1.333 \mathrm{mmol} \mathrm{L}^{-1}$, then removal efficiency of $\mathrm{As}(\mathrm{v})$ in water was reduced about $80 \%$ on MgAlFe$\mathrm{CLDH}, \mathrm{MgAlFe}-\mathrm{Cl}-\mathrm{LDH}$, and $\mathrm{MgAlFe}-\mathrm{NO}_{3}-\mathrm{LDH}$. When the concentration of phosphate in the water increased to $13.33 \mathrm{mmol} \mathrm{L}{ }^{-1}$, then removal efficiency of $\mathrm{As}(\mathrm{v})$ decreased about $90 \%$. Those were similar to results reported previously, ${ }^{53}$ and the reason that phosphate more significantly affects the efficiency of arsenic removal is because it competes for 

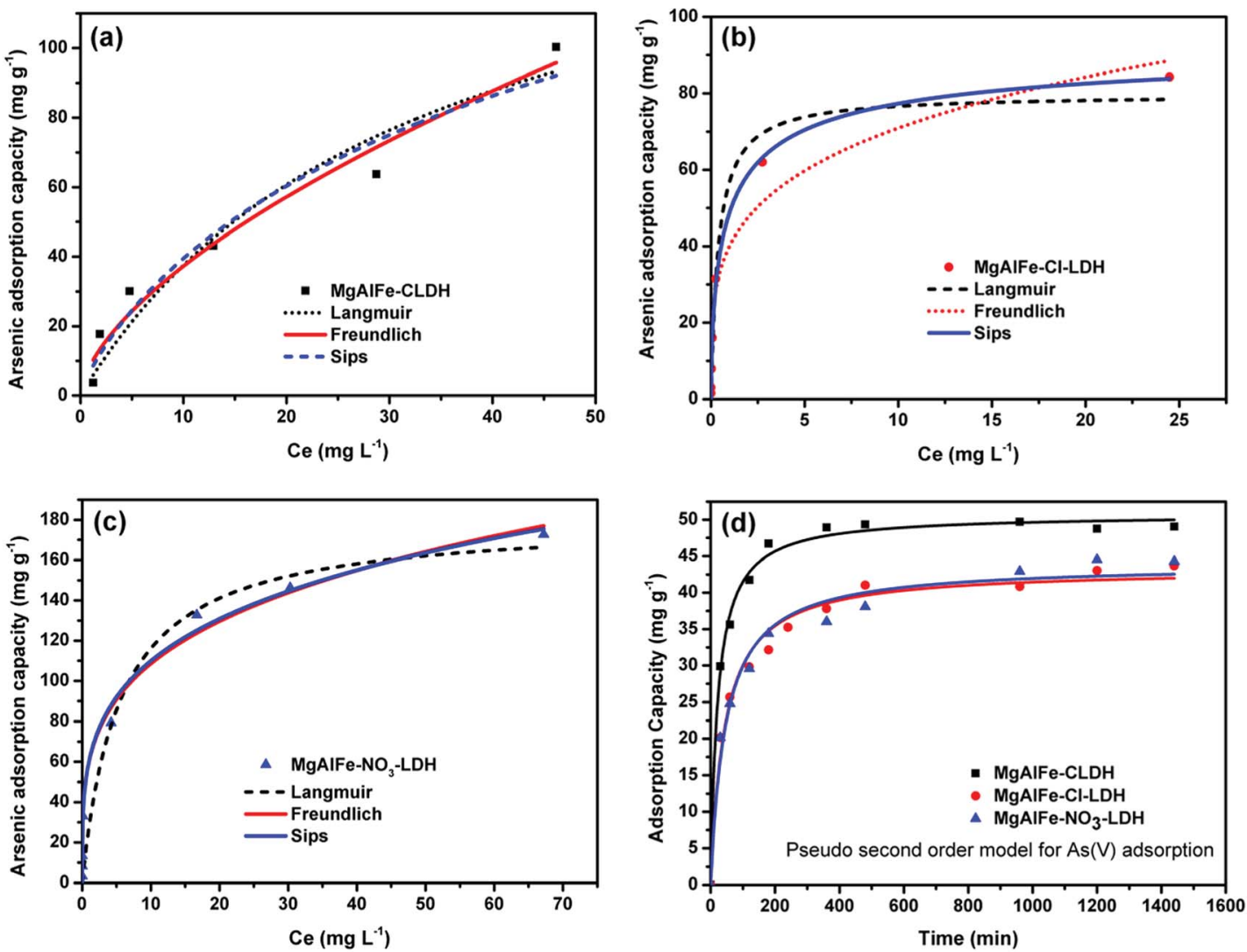

Fig. 4 (a) Isothermal study of adsorption of arsenic with MgAlFe-CLDH. (b) Isothermal study of adsorption of arsenic with MgAlFe-Cl-LDH. (c) Isothermal study of adsorption of arsenic with MgAlFe- $\mathrm{NO}_{3}-\mathrm{LDH}$. (d) Kinetic fitting curve of arsenic adsorption on the three materials.

adsorption. ${ }^{54,55}$ This can be explained by the similar tetrahedral structures of arsenate and phosphate while the presence of nitrate and chloride ions, lacking a tetrahedral structure, have little effect on the removal efficiency of arsenate. This also could be ascribed to the fact that these ions are monovalent and have lower ionic potential, resulting in their weaker competition ability with $\mathrm{As}(\mathrm{v}) .{ }^{56}$ Carbonate and sulfate have little effect on the adsorption of arsenic by MgAlFe-CLDH, but a higher concentration of carbonate and sulfate can significantly reduce adsorption efficiency of MgAlFe-Cl-LDH and $\mathrm{MgAlFe}-\mathrm{NO}_{3}-\mathrm{LDH}$ to arsenate. When the concentration of carbonate or sulfate in water was $13.33 \mathrm{mmol} \mathrm{L}^{-1}$, then removal efficiency of As(v) was reduced about $60 \%$ on $\mathrm{MgAlFe}-\mathrm{Cl}-\mathrm{LDH}$ and $\mathrm{MgAlFe}-\mathrm{NO}_{3}-\mathrm{LDH}$.
High concentrations of carbonate or sulfate can affect the exchange of chloride (or nitrate) ions in the material layers with arsenate in water.

Effect of adsorbent dosage and $\mathrm{pH}$ on arsenic adsorption. The effect of the adsorbent dosage on removal efficiency of arsenic was evaluated by gradually increasing the dosage of the material in an experiment. The results of the experiment are shown in Fig. S4. $\dagger$ It can be seen from Fig. S4 $\uparrow$ that an increasing amount of material increases the removal rate of arsenate. When the MgAlFe- $\mathrm{NO}_{3}-\mathrm{LDH}$ dosage was $0.4 \mathrm{~g} \mathrm{~L}^{-1}$, then the removal rate reached $99.9 \%$ and the remaining arsenic concentration was below $10 \mu \mathrm{g} \mathrm{L} \mathrm{L}^{-1}$. When the dosage of MgAlFe-Cl-LDH reached $1 \mathrm{~g} \mathrm{~L}^{-1}$, then the removal rate was
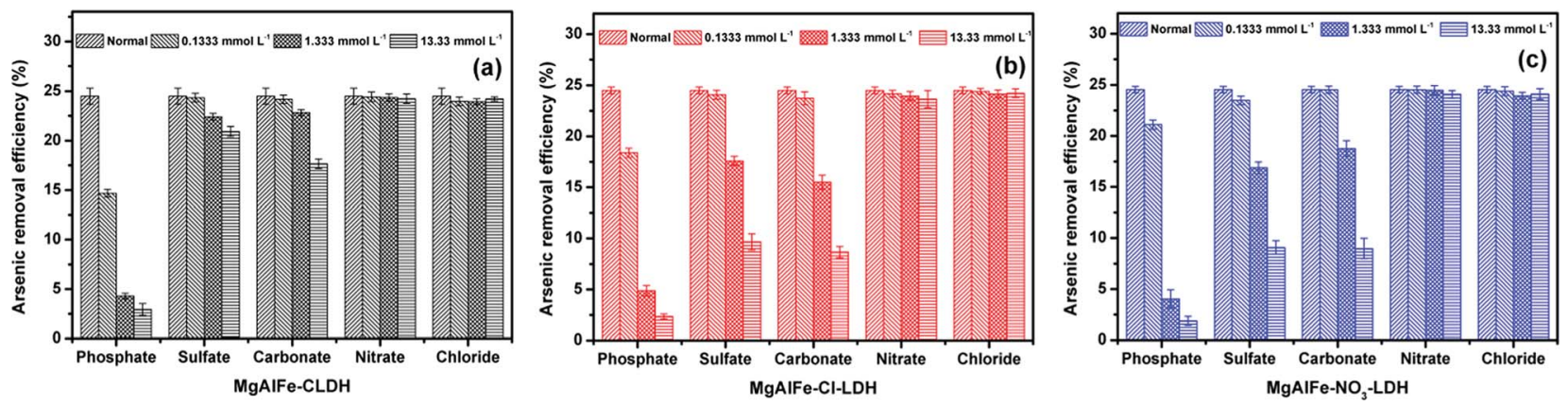

Fig. 5 Effect of coexisting anions on arsenic removal by materials in water. (a) MgAlFe-CLDH. (b) MgAlFe-Cl-LDH. (c) MgAlFe-NO${ }_{3}-\mathrm{LDH}$. 

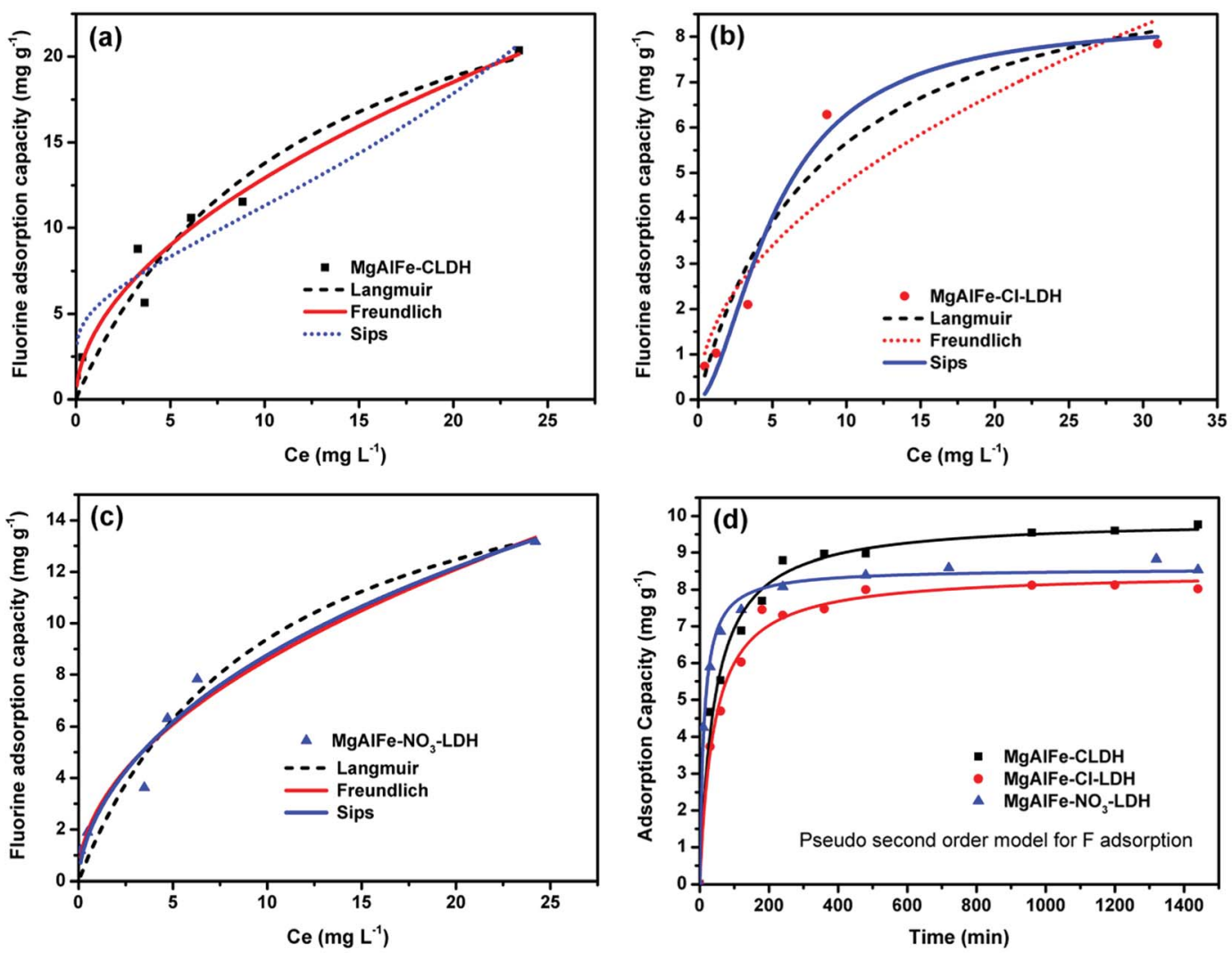

Fig. 6 (a) Isothermal study of adsorption of fluoride with MgAlFe-CLDH. (b) Isothermal study of adsorption of fluoride with MgAlFe-Cl-LDH. (c) Isothermal study of adsorption of fluoride with $\mathrm{MgAlFe}-\mathrm{NO}_{3}-\mathrm{LDH}$. (d) Kinetic fitting curve of fluoride adsorption on the three materials.

about $99.8 \%$ and the concentration of residual arsenate was also lower than $10 \mu \mathrm{g} \mathrm{L}^{-1}$. However, when the concentration of MgAlFe-CLDH was $0.1 \mathrm{~g} \mathrm{~L}^{-1}$, the same effect could be achieved. The above situation meets the World Health Organization's, EPA's, and China's drinking water standards for concentration of arsenic limit requirements. Effects of initial solution $\mathrm{pH}$ on arsenate adsorption are shown in Fig. S4b † where it can be seen that the effect of $\mathrm{pH}$ on the adsorption of arsenate by MgAlFeCLDH can be neglected in an initial pH range from 3 to 10 . With an increase of $\mathrm{pH}$, the adsorption capacity decreases slowly and may be related to the electrostatic repulsion of arsenate and the surfaces of MgAlFe-Cl-LDH and MgAlFe- $\mathrm{NO}_{3}-$ LDH.

\section{Adsorption of fluoride}

Isotherms of fluoride adsorption. Relevant data obtained from the isothermal adsorption experiments with fluoride were analyzed and fitted and the obtained fitting curves are shown in Fig. 6a-c. Relevant parameters were also calculated, as shown in Table S3. $\dagger$ It can be seen from Fig. 6 and Table S3 $\uparrow$ that the data of MgAlFe-CLDH adsorbed fluoride was more consistent with a Freundlich isothermal equation, while the adsorption of fluoride on MgAlFe-Cl-LDH or MgAlFe- $\mathrm{NO}_{3}$ - $\mathrm{LDH}$ was more consistent with a Sips adsorption isotherm equation. The above results are similar to the adsorption of arsenic which indicates that the mechanism of adsorption of arsenate and fluoride are also similar.
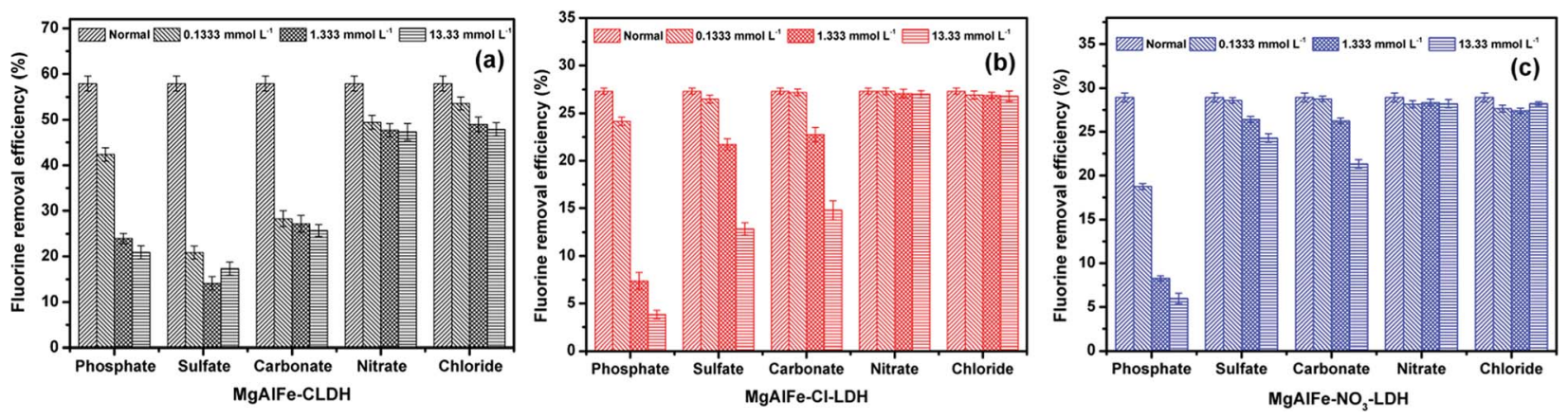

Fig. 7 Effect of coexisting anions on fluoride removal by materials in water. (a) MgAlFe-CLDH; (b) MgAlFe-Cl-LDH; (c) MgAlFe-NO $3-\mathrm{LDH}$. 

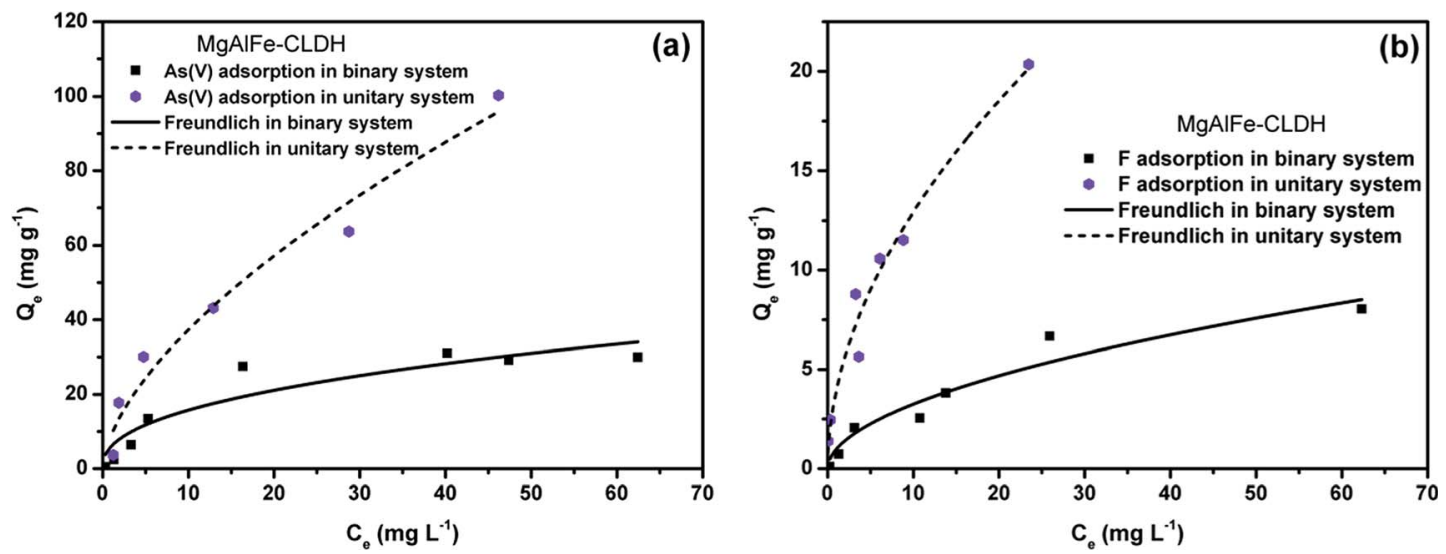

Fig. 8 (a) Isothermal study of adsorption of arsenateon MgAlFe-CLDH in coexistence with fluoride. (b) Isothermal study of adsorption of fluoride with MgAlFe-CLDH in coexistence with arenate.
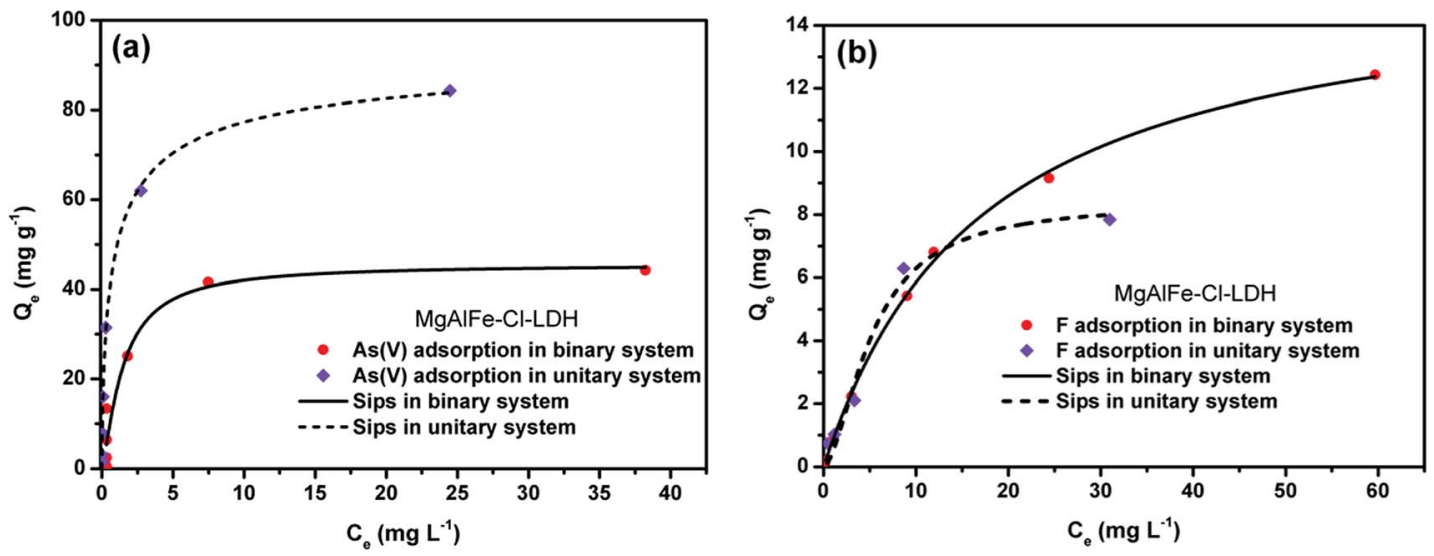

Fig. 9 (a) Isothermal study of adsorption of arsenate on MgAlFe-Cl-LDH in coexistence with fluoride. (b) Isothermal study of adsorption of fluoride with $\mathrm{MgAlFe}-\mathrm{Cl}-\mathrm{LDH}$ in coexistence with arsenate.

Kinetics of fluoride adsorption. The fitting curves of the adsorption kinetics of fluoride on the three materials are shown in Fig. 6d and the obtained fitting parameters are shown in Table $\mathrm{S} 4 \dagger$ where it can be seen that the fluoride adsorption rates on these materials were very fast in the first 3 hours. MgAlFe$\mathrm{NO}_{3}-\mathrm{LDH}$ is faster than MgAlFe-Cl-LDH and MgAlFe-CLDH when achieving the adsorption equilibrium of fluoride. This suggests that inter granular nitrate ions are more likely to
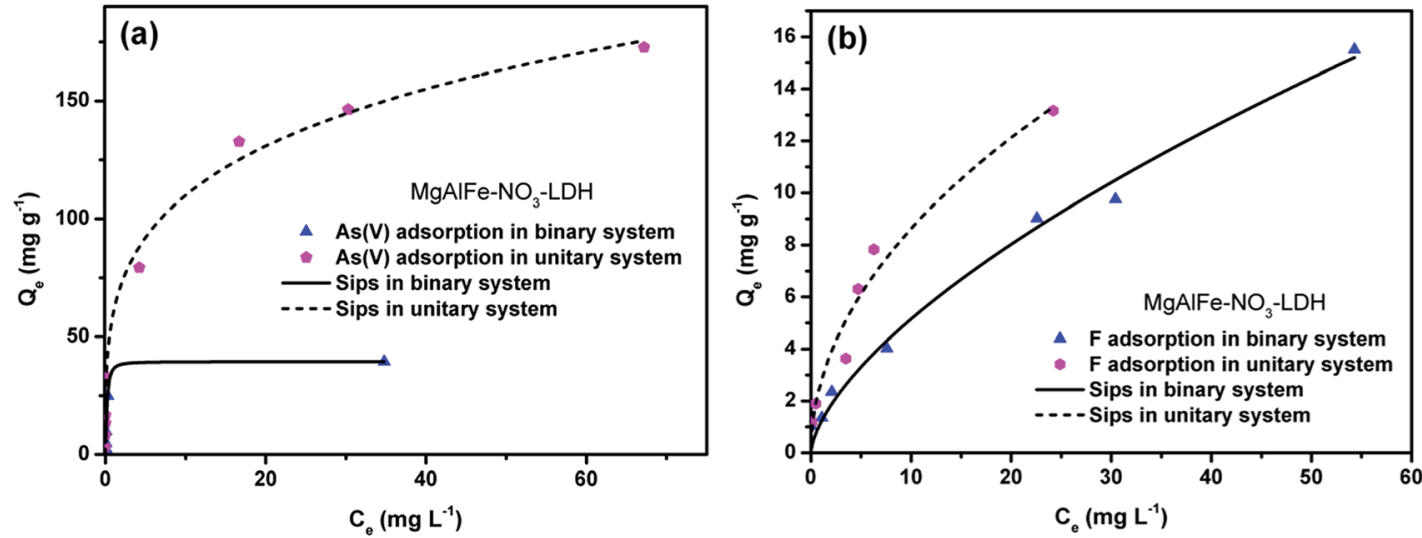

Fig. 10 (a) Isothermal study of adsorption of arsenateon MgAlFe- $\mathrm{NO}_{3}-\mathrm{LDH}$ in coexistence with fluoride. (b) Isothermal study of adsorption of fluoride with $\mathrm{MgAlFe}-\mathrm{NO}_{3}-\mathrm{LDH}$ in coexistence with arsenate. 




Fig. 11 Effect of $\mathrm{MgAlFe}-\mathrm{NO}_{3}-\mathrm{LDH}$ dosage on the adsorption of $\mathrm{As}(\mathrm{v})$ and $\mathrm{F}^{-}$binary system.

Table 2 Desorption rate of $\mathrm{MgAlFe}-\mathrm{NO}_{3}-\mathrm{LDH}$ adsorbed arsenate and fluoride

\begin{tabular}{lcc}
\hline & \multicolumn{2}{c}{ Desorption rate (\%) } \\
\cline { 2 - 3 } Desorption solution & $\mathrm{As}(\mathrm{v})$ & $\mathrm{F}$ \\
\hline $\mathrm{H}_{2} \mathrm{O}$ & 0 & 0 \\
$\mathrm{NaOH}$ & 3.26 & 18.21 \\
$\mathrm{Na}_{2} \mathrm{CO}_{3}$ & 1.789 & 70.61 \\
$\mathrm{Na}_{2} \mathrm{HPO}_{4}$ & 25.1 & 59.84 \\
\end{tabular}

undergo ion exchange with fluoride ions and have faster exchange rates. In order to further explore the adsorption process, a pseudo-first order kinetic model and pseudo-second order kinetic model were used to fit the relevant data of the fluoride adsorption kinetics experiment. As shown in Table $\mathrm{S} 4, \uparrow$ correlation coefficients of the three materials with the pseudosecond order kinetic equation model are larger than those of the pseudo-first order kinetic equation. This suggests that the pseudo-second order kinetic model better reflects the adsorption of fluoride.

Effects of anions on fluoride adsorption. The $\mathrm{PO}_{4}{ }^{3-}, \mathrm{SO}_{4}{ }^{2-}$, $\mathrm{CO}_{3}{ }^{2-}, \mathrm{NO}_{3}{ }^{-}$, and $\mathrm{Cl}^{-}$ions were selected as coexisting ion influencing factors. Effects of excess anions on the adsorption of fluoride on the materials were investigated and the experimental results are shown in Fig. 7. The presence of phosphate can significantly affect the removal efficiency of fluoride in water. When the phosphate content in water was $1.333 \mathrm{mmol}$ $\mathrm{L}^{-1}$, the removal efficiency of fluoride in water was reduced about $70 \%$ on the MgAlFe-CLDH, MgAlFe-Cl-LDH, and MgAlFe- $\mathrm{NO}_{3}-\mathrm{LDH}$. The mechanism of the effect of phosphate on the adsorption of fluoride on materials was similar to the mechanism by which phosphate affects the adsorption of arsenate. Because $\mathrm{p} K_{2}$ of phosphoric acid is 7.21 , under the experimental conditions ( $\mathrm{pH}=6.0)$, the main form of phosphate is $\mathrm{H}_{2} \mathrm{PO}_{4}{ }^{-}$, which can also produce strong competitive adsorption with fluoride ion $\mathrm{s}^{57}$ while the presence of nitrate and chloride ions have little effect on the removal efficiency of fluoride. Also, carbonate and sulfate have little effect on the adsorption of fluoride by MgAlFe- $\mathrm{NO}_{3}-\mathrm{LDH}$, but a higher concentration of carbonate or sulfate $\left(13.33 \mathrm{mmol} \mathrm{L}^{-1}\right)$ can significantly reduce the adsorption efficiency of $\mathrm{MgAlFe}-\mathrm{Cl}-$ LDH to fluoride (about 50\%). It is noteworthy that the presence of lower concentrations of carbonate or sulfate in water can significantly affect the removal of fluoride by MgAlFeCLDH. The reason may be that the carbonate or sulfate is structurally reconstituted with CLDH. This process has a significant effect on the adsorption of fluoride ions on the materials.

Effect of adsorbent dosage and $\mathrm{pH}$ on fluoride adsorption. Effects of dosage of different materials on the removal efficiency of fluoride were evaluated by gradually increasing the dosage of the material in the experiments and results of the experiments are shown in Fig. S5a. $\dagger$ Effects of the initial pH of solution on the adsorption of fluoride on materials were also studied and results are shown in Fig. S5b. $\dagger$ With an increase of material dosage, removal efficiency of fluoride ions in water increases. When the dosages of MgAlFe-CLDH and $\mathrm{MgAlFe}-\mathrm{NO}_{3}-\mathrm{LDH}$ reached $2.0 \mathrm{~g} \mathrm{~L}^{-1}$, the removal rate of fluoride ions in water reached more than $95 \%$. The fluoride adsorption capacity of the material tends to decrease slowly with increasing $\mathrm{pH}$. This may be related to a weak electrical repulsion between the surfaces of the materials and fluoride ions.

Isothermal study for simultaneous adsorption of arsenic and fluoride. Isothermal experiments of arsenate and fluoride ion coexistent systems were carried out, data fitting curves are shown in Fig. 8-10, and the calculated relevant parameters are shown in Table S5. $\dagger$ It can be seen from Fig. 8, that the equilibrium adsorption capacity $\left(Q_{\mathrm{e}}\right)$ for arsenate and fluorine on MgAlFe-CLDH in a coexistant (binary) system is lower than that in a single (unitary) system due to the presence of competitive
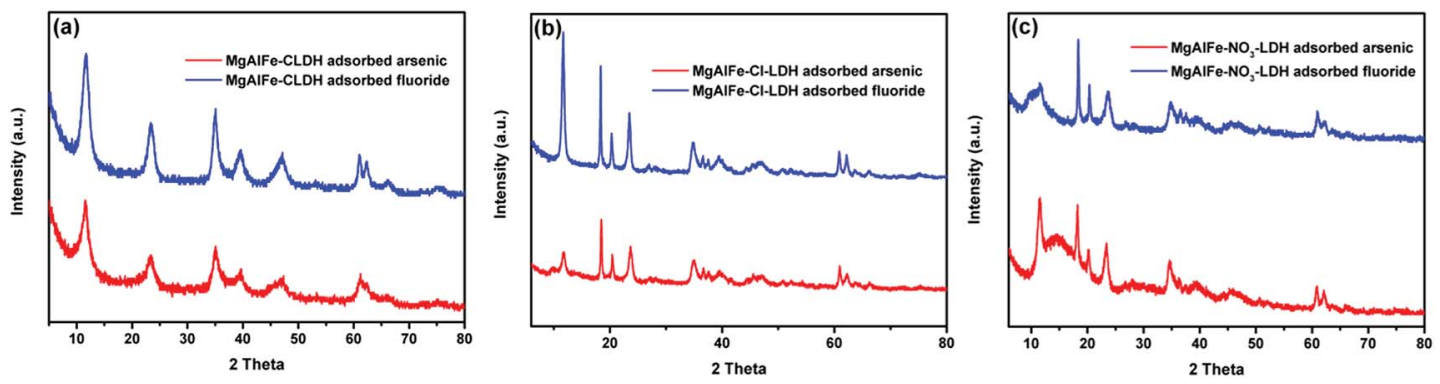

Fig. 12 XRD patterns of materials after adsorption arsenate and fluoride. (a) MgAlFe-CLDH. (b) MgAlFe-Cl-LDH. (c) MgAlFe-NO $3-\mathrm{LDH}$. 


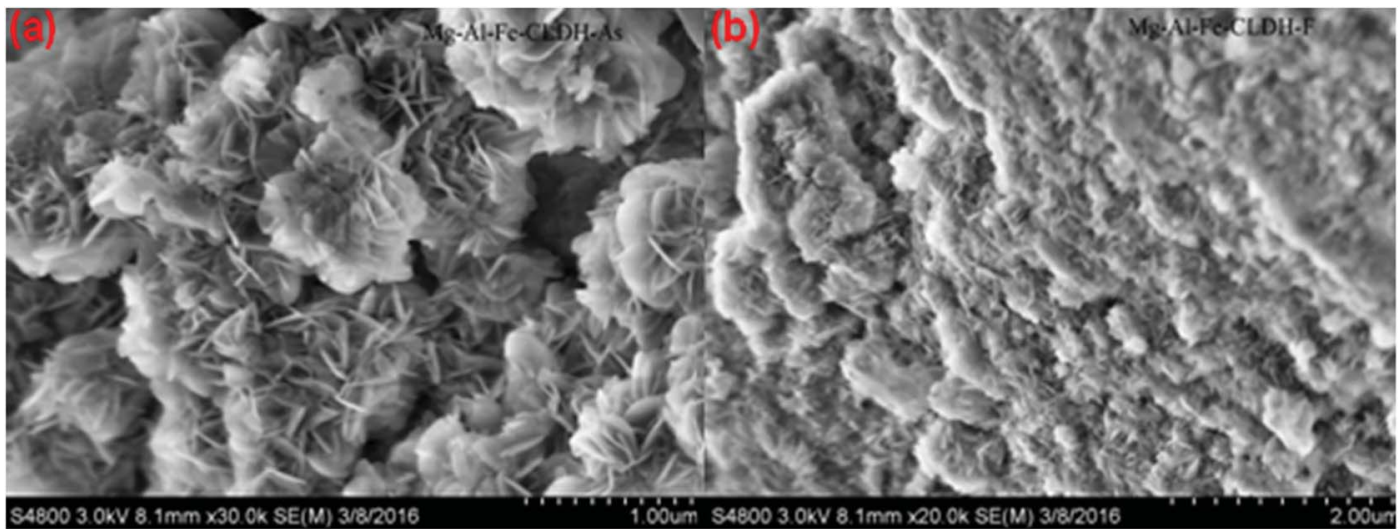

Fig. 13 (a) SEM image of MgAlFe-CLDH after adsorption of arsenate. (b) SEM image of Mg-Al-Fe-CLDH after adsorption of fluoride.

adsorption. It is noteworthy that the adsorption behavior of arsenate and fluoride in a material is consistent with the Freundlich adsorption isothermal equation, whether it is a single (unitary) system or a coexistent (binary) system. Adsorption isotherms of arsenic and fluorine adsorbed on MgAlFe-CLDH are shown in Fig. 9. It can be seen from Fig. 9 the adsorption behavior of arsenate and fluoride on the MgAlFe-ClLDH material is consistent with the Sips model, whether it is a unitary or binary system. The equilibrium adsorption capacity $\left(Q_{\mathrm{e}}\right)$ for arsenate on MgAlFe-Cl-LDH in the binary system is lower than that in the unitary system due to the presence of competitive adsorption. Interestingly, the equilibrium adsorption capacity $\left(Q_{\mathrm{e}}\right)$ for fluoride on MgAlFe-Cl-LDH in the binary system is higher than that in the unitary system and the maximum adsorption capacity $\left(Q_{\mathrm{m}}\right)$ of fluoride in the binary system is higher than that of the single system. It is shown that fluoride has an advantage over competitive adsorption in the coexisting system and occupies more adsorbable sites on MgAlFe-Cl-LDH in the adsorption process. The adsorption of arsenate and fluoride on $\mathrm{MgAlFe}-\mathrm{NO}_{3}-\mathrm{LDH}$ isothermal data fitting curves are shown in Fig. 10 which shows that the adsorption behaviors of arsenate and fluoride on the MgAlFe$\mathrm{NO}_{3}-\mathrm{LDH}$ material are consistent with the Sips adsorption isothermal equation. The equilibrium adsorption capacity $\left(Q_{\mathrm{e}}\right)$ for arsenate and fluorine on $\mathrm{MgAlFe}-\mathrm{NO}_{3}-\mathrm{LDH}$ in the binary system was lower than that in the unitary system due to the presence of competitive adsorption. It is noteworthy that the maximum adsorption capacity $\left(Q_{\mathrm{m}}\right)$ of fluoride in the binary system was higher than that of the single system. Data also showed that fluoride in the coexisting system occupied more adsorbable sites on the material than arsenate.

Simultaneous removal of arsenate and fluoride. The effect of MgAlFe- $\mathrm{NO}_{3}-\mathrm{LDH}$ dosage on adsorption of the arsenate and fluoride binary system was studied and results are shown in Fig. 11. It was found that a competitive adsorption behaviour between arsenate and fluoride on $\mathrm{MgAlFe}-\mathrm{NO}_{3}-\mathrm{LDH}$ occurred in the experiment within a dosage range of $0.2-1.5 \mathrm{~g} \mathrm{~L}^{-1}$ when the initial concentrations of arsenate and fluoride were the same $2 \mathrm{mg} \mathrm{L}^{-1}$. The removal rate of fluoride and arsenate increased with an increase in the dosage of MgAlFe- $\mathrm{NO}_{3}-\mathrm{LDH}$. When the adsorbent dosage was $1.5 \mathrm{~g} \mathrm{~L}^{-1}$, the removal rate of fluoride and arsenate were $99.44 \%$ and $99.8 \%$, respectively. The remaining concentration of arsenic was less than $10 \mu \mathrm{g} \mathrm{L} \mathrm{L}^{-1}$ and the remaining fluoride ion concentration was below $100 \mu \mathrm{g} \mathrm{L}^{-1}$ which meets the World Health Organization's, EPA's and China's drinking water standards for both arsenic and fluoride concentration limit requirements. It can be found from the image of SEM (Fig. S6a $\dagger$ ) that $\mathrm{MgAlFe}-\mathrm{NO}_{3}-\mathrm{LDH}$ after
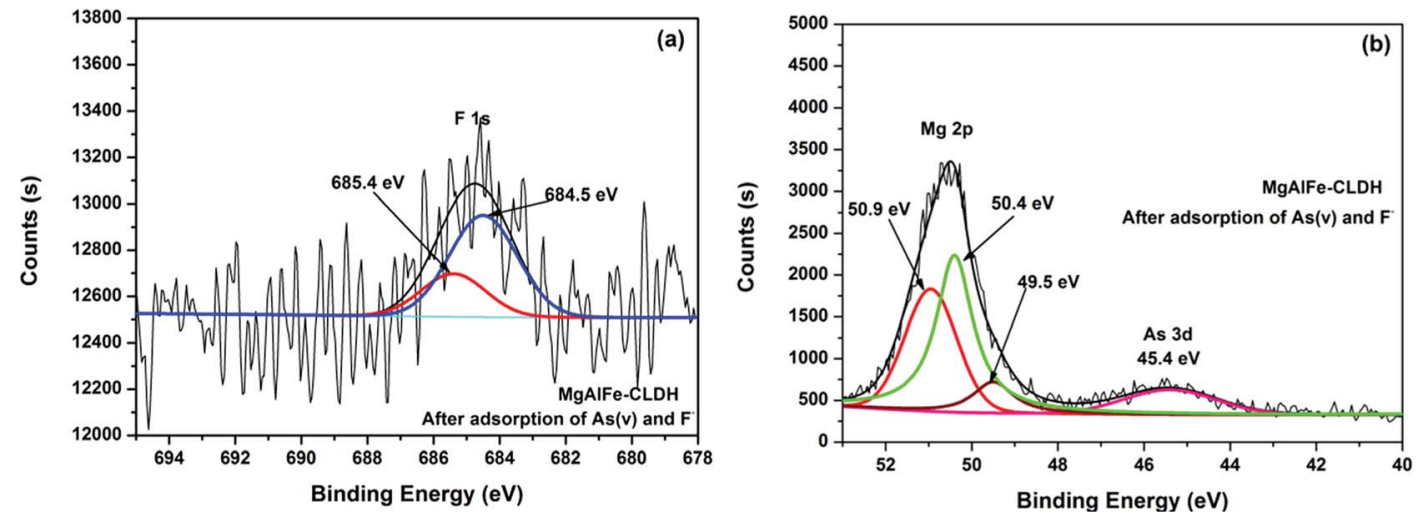

Fig. 14 (a) XPS spectra of MgAlFe-CLDH after adsorption of As(v) and $\mathrm{F}^{-}$peak of $\mathrm{F}$ 1s. (b) XPS spectra of MgAlFe-CLDH after adsorption of As(v) and $\mathrm{F}^{-}$peak of $\mathrm{Mg} 2 \mathrm{p}$ and $\mathrm{As} 3 \mathrm{~d}$. 

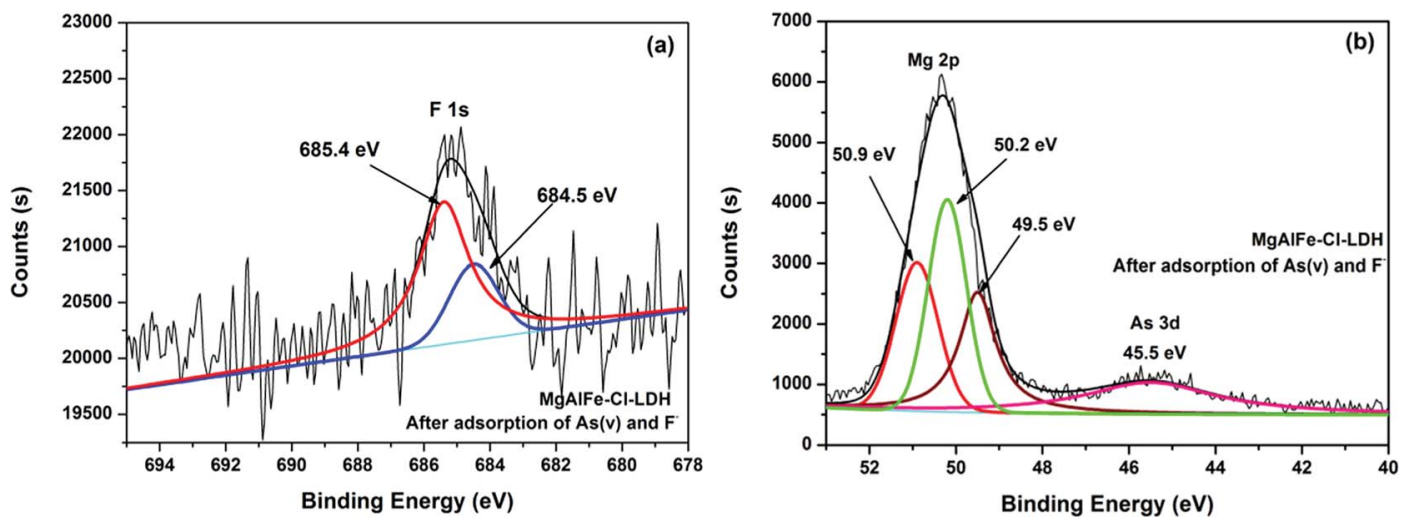

Fig. 15 (a) XPS spectra of MgAlFe-Cl-LDH after adsorption of As(v) and $\mathrm{F}^{-}$peak of $\mathrm{F} 1 \mathrm{~s}$. (b) XPS spectra of MgAlFe-Cl-LDH after adsorption of $\mathrm{As}(\mathrm{v})$ and $\mathrm{F}^{-}$peak of $\mathrm{Mg} 2 \mathrm{p}$ and $\mathrm{As} 3 \mathrm{~d}$.

adsorption of arsenate and fluoride remained in a sheet structure. The EDS analysis (Fig. S6b $\dagger$ ) showed that composition of arsenic and fluorine existed on the surface of the adsorbent.

Desorption. In order to investigate stability and the possibility of adsorbent materials after adsorption of arsenate and fluoride, $100 \mathrm{mg} \mathrm{L}^{-1}$ solutions of $\mathrm{NaOH}, \mathrm{Na}_{2} \mathrm{CO}_{3}$, and $\mathrm{Na}_{2} \mathrm{HPO}_{4}$ were separately used as eluants. The results are listed in Table 2 which shows that when $\mathrm{NaOH}, \mathrm{Na}_{2} \mathrm{CO}_{3}$, or $\mathrm{Na}_{2} \mathrm{HPO}_{4}$ solution are the eluent, some arsenate will be eluted, but the desorption rate is not high. The desorption rate of fluoride ions was higher than that of adsorbed arsenate which indicates that arsenate had a greater affinity for $\mathrm{MgAlFe}-\mathrm{NO}_{3}-\mathrm{LDH}$ than fluoride, and was more difficult to release.

Mechanism. The XRD patterns of the three synthesized materials after adsorption of the target ions of arsenate or fluoride are shown in Fig. 12 where it can be seen that MgAlFeCLDH had obvious lamellar structure characteristic peaks of $\mathrm{LDH}$ after the $\mathrm{As}(\mathrm{v})$ or $\mathrm{F}^{-}$adsorption. From the SEM photograph of Fig. 13, it was clear that the material had a more lamellar structure after adsorption of arsenic. It was further explained that the adsorption process of CLDH on arsenate and fluoride ions was mainly the process of reconstructing the LDH structure with arsenate or fluoride ion intercalation. The XRD patterns of MgAlFe-Cl-LDH and MgAlFe- $\mathrm{NO}_{3}-\mathrm{LDH}$ adsorbed arsenic or fluoride are shown in Fig. 12b and c where it can be seen that the lamellar structure of the material did not change significantly. The adsorption process included surface adsorption and interlayer ion exchange.

Fig. 14a shows the XPS spectra of MgAlFe-CLDH after adsorption. It can be seen from Fig. 14a that fluorine was present in the form of $\mathrm{F}^{-}$due to peaks at $685.4 \mathrm{eV}(\mathrm{F}-\mathrm{Mg}-\mathrm{F})$ and $684.5 \mathrm{eV}(\mathrm{F}-\mathrm{Na}-\mathrm{F}){ }^{58,59}$ It also can be seen from Fig. 14b that magnesium exists in a positive divalent form; the main forms are $\mathrm{Mg}-\mathrm{O}(50.2 \mathrm{eV}),{ }^{60} \mathrm{~F}-\mathrm{Mg}-\mathrm{F}(50.9 \mathrm{eV}),{ }^{61}$ and $\mathrm{Mg}(\mathrm{OH})_{2}(49.5$ eV). ${ }^{62}$ Arsenic adsorbed on the surface of MgAlFe-CLDH exists in the form of $\mathrm{HAsO}_{4}{ }^{2-}$ deduced because of presence of the peak near $45.5 \mathrm{eV} .{ }^{58}$ From Fig. 15, it shown that the surface features of MgAlFe-Cl-LDH are similar to those of MgAlFe-CLDH after simultaneous adsorption of arsenic and fluoride.

Fig. 16 shows that the state of partial fluorine existing on the surface of $\mathrm{MgAlFe}-\mathrm{NO}_{3}-\mathrm{LDH}$ exists in a special form. ${ }^{63}$ Arsenic adsorbed on $\mathrm{MgAlFe}-\mathrm{NO}_{3}$ - $\mathrm{LDH}$ exists in the form of $\mathrm{HAsO}_{4}{ }^{2-}$, but it may also exist in other forms. The peak at $49.4 \mathrm{eV}$ represents a similar form of $\mathrm{AsF}_{6}{ }^{-58,64}$ This indicated that unlike the former two MgAlFe-Cl-LDH and MgAlFe-CLDH materials, the effect of arsenic and fluorine on the surface of MgAlFe- $\mathrm{NO}_{3}$-LDH may be stronger. The interaction among arsenate, fluoride, and surface composition of the adsorbent is
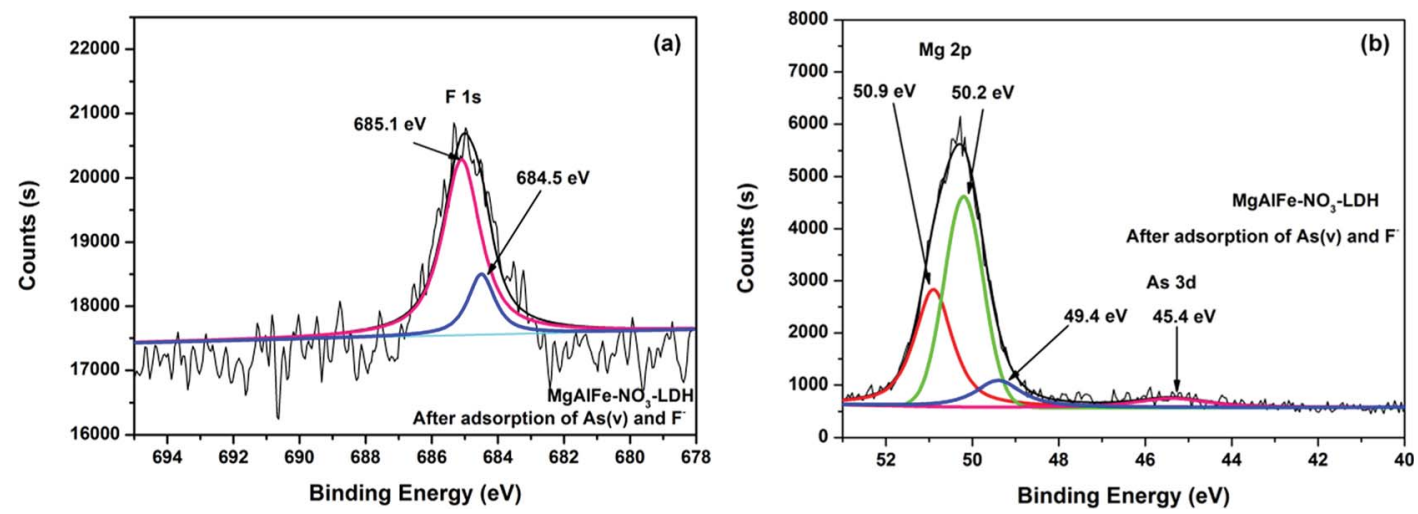

Fig. 16 (a) XPS spectra of MgAlFe- $\mathrm{NO}_{3}-\mathrm{LDH}$ after adsorption of $\mathrm{As}(\mathrm{V})$ and $\mathrm{F}^{-}$peak of $\mathrm{F} 1 \mathrm{~s}$. (b) XPS spectra of $\mathrm{MgAlFe}^{-\mathrm{NO}} \mathrm{O}_{3}-\mathrm{LDH}$ after adsorption of $\mathrm{As}(\mathrm{V})$ and $\mathrm{F}^{-}$peak of $\mathrm{Mg} 2 \mathrm{p}$ and $\mathrm{As} 3 \mathrm{~d}$. 
more intense during the simultaneous adsorption on $\mathrm{MgAlFe}-$ $\mathrm{NO}_{3}-\mathrm{LDH}$ which may be the reason why $\mathrm{MgAlFe}-\mathrm{NO}_{3}-\mathrm{LDH}$ is more efficient in simultaneously removing arsenic and fluorine. This also makes arsenic and fluorine adsorbed on the material more stable and not easily desorbed.

\section{Conclusions}

Adsorption of arsenate and fluoride on MgAlFe-CLDH was consistent with the Freundlich adsorption isotherm equation both in a single pollutant system and composite pollutant system. However, the adsorption of arsenate and fluoride on MgAlFe-Cl-LDH or MgAlFe- $\mathrm{NO}_{3}-\mathrm{LDH}$ meet the Sips adsorption isothermal equation. During the simultaneous removal process in a mixed pollutant system, arsenic and fluoride compete for adsorption sites on the material, and the results showed that fluoride is more advantageous in the competition with $\mathrm{MgAlFe}-$ $\mathrm{Cl}-\mathrm{LDH}$ and $\mathrm{MgAlFe}-\mathrm{NO}_{3}-\mathrm{LDH}$. The interaction between arsenic and fluoride on nitrate-intercalated LDHs was stronger, which may be the reason why nitrate-intercalated LDHs perform better on the efficiency of simultaneous adsorption. MgAlFe- $\mathrm{NO}_{3}-\mathrm{LDH}$ was used to adsorb arsenate and fluoride in a coexistent system with a concentration of $2 \mathrm{mg} \mathrm{L}^{-1}$ for each pollutant and a dosage of the adsorbent material of $1.5 \mathrm{~g} \mathrm{~L}^{-1}$. After the adsorption, the remaining concentration of arsenic was less than $10 \mu \mathrm{g} \mathrm{L}^{-1}$ and the remaining fluoride ion concentration was below $20 \mu \mathrm{g} \mathrm{L}^{-1}$ which meets the World Health Organization's, EPA's, and China's drinking water standards for both arsenic and fluoride concentration limit requirements.

\section{Conflicts of interest}

There are no conflicts to declare.

\section{Acknowledgements}

Financial support was obtained from the Swedish Research Council via the contract Dnr. 639-2013-6913, the International Science and Technology Cooperation Program of China (2016YFE0123700) and China Postdoctoral Science Foundation (No. 2017M621529).

\section{References}

1 A. M. Khair, C. C. Li, Q. H. Hu, X. B. Gao and Y. X. Wanga, Geochem. Int., 2014, 52, 868-881.

2 C. Gonzalez-Horta, L. Ballinas-Casarrubias, B. SanchezRamirez, M. C. Ishida, A. Barrera-Hernandez, D. GutierrezTorres, O. L. Zacarias, R. J. Saunders, Z. Drobna, M. A. Mendez, G. Garcia-Vargas, D. Loomis, M. Styblo and L. M. Del Razo, Int. J. Environ. Res. Public Health, 2015, 12, 4587-4601.

3 A. Rasool, T. F. Xiao, Z. T. Baig, S. Masood, K. M. G. Mostofa and M. Iqbal, Environ. Sci. Pollut. Res., 2015, 22, 1972919746.

4 A. Shahab, S. Qi and M. Zaheer, Environ. Sci. Pollut. Res., 2018, DOI: 10.1007/s11356-018-2320-8.
5 E. Hayat and A. Baba, Environ. Monit. Assess., 2017, 189, 318. 6 M. Kumar, A. Das, N. Das, R. Goswami and U. K. Singh, Chemosphere, 2016, 150, 227-238.

7 M. T. Alarcon-Herrera, J. Bundschuh, B. Nath, H. B. Nicolli, M. Gutierrez, V. M. Reyes-Gomez, D. Nunez, I. R. MartinDominguez and O. Sracek, J. Hazard. Mater., 2013, 262, 960-969.

8 M. I. Jimenez-Cordova, L. C. Sanchez-Pena, T. Matousek, E. Villarreal, M. Cardenas-Gonzalez, A. Barrera-Hernandez, M. C. Gonzalez-Horta, O. C. Barbier and L. M. Del Razo, Toxicol. Lett., 2016, 259, S121.

9 E. E. Villarreal-Vega, M. I. Jimenez-Cordova, L. C. SanchezPena, J. Narvaez-Morales, A. Barrera-Hernandez, M. Cardenas-Gonzalez, L. M. Del Razo, M. C. GonzalezHorta and O. Barbier, Toxicol. Lett., 2016, 259, S133-S134.

10 H. Khan, Y. Verma and S. V. S. Rana, Cancer Med., 2018, 7, 33.

11 Y. P. Zhu, S. H. Xi, M. Y. Li, T. T. Ding, N. Liu, F. Y. Cao, Y. Zeng, X. J. Liu, J. W. Tong and S. F. Jiang, NeuroToxicology, 2017, 59, 56-64.

12 S. V. Jadhav, E. Bringas, G. D. Yadav, V. K. Rathod, I. Ortiz and K. V. Marathe, J. Environ. Manage., 2015, 162, 306-325.

13 L. S. Thakur and P. Mondar, J. Environ. Manage., 2017, 190, 102-112.

14 T. C. Prathna, S. K. Sharma and M. Kennedy, Desalin. Water Treat., 2017, 67, 187-195.

15 L. Yan, H. W. Tu, T. S. Chan and C. Y. Jing, Chem. Eng. J., 2017, 313, 983-992.

16 B. D. Xi, X. W. Wang, W. J. Liu, X. F. Xia, D. S. Li, L. S. He, H. M. Wang, W. J. Sun, T. X. Yang and W. Tao, Sep. Sci. Technol., 2014, 49, 2642-2649.

17 R. C. Hott, L. F. O. Maia, M. S. Santos, M. C. Faria, L. C. A. Oliveira, M. C. Pereira, C. A. Bomfeti and J. L. Rodrigues, Environ. Sci. Pollut. Res., 2018, 25, 1385713867.

18 J. Y. Zhao, H. M. Guo, J. Ma and Z. L. Shen, Int. J. Phytorem., 2015, 17, 355-362.

19 K. D. Brahman, T. G. Kazi, J. A. Baig, H. I. Afridi, S. S. Arain, S. Saraj, M. B. Arain and S. A. Arain, Chemosphere, 2016, 150, 320-328.

20 V. K. Rathore and P. Mondal, Ind. Eng. Chem. Res., 2017, 56, 8081-8094.

21 V. K. Rathore, D. K. Dohare and P. Mondal, J. Environ. Chem. Eng., 2016, 4, 2417-2430.

22 S. Bibi, A. Farooqi, K. Hussain and N. Haider, J. Cleaner Prod., 2015, 87, 882-896.

23 H. M. Guo, L. J. Yang and X. Q. Zhou, Sep. Sci. Technol., 2014, 49, 2412-2425.

24 P. P. Huang, C. Y. Cao, F. Wei, Y. B. Sun and W. G. Song, $R S C$ Adv., 2015, 5, 10412-10417.

25 D. J. Kang, X. L. Yu, S. R. Tong, M. F. Ge, J. C. Zuo, C. Y. Cao and W. G. Song, Chem. Eng. J., 2013, 228, 731-740.

26 F. Cavani, F. Trifirò and A. Vaccari, Catal. Today, 1991, 11, 173-301.

27 K.-H. Goh, T.-T. Lim and Z. Dong, Water Res., 2008, 42, 13431368. 
28 J. Wang, T. Zhang, M. Li, Y. Yang, P. Lu, P. Ning and Q. Wang, RSC Adv., 2018, 8, 22694-22709.

29 T. Zhang, H. Yu, Y. Zhou, J. Rong, Z. Mei and F. Qiu, Korean J. Chem. Eng., 2016, 33, 720-725.

30 S. P. Suriyaraj and R. Selvakumar, $R S C A d v ., 2016,6$, 1056510583.

31 M. Pigna, J. J. Dynes, A. Violante, A. Sommella and A. G. Caporale, Environ. Eng. Sci., 2016, 33, 98-104.

32 Z. Sun, J.-S. Park, D. Kim, C.-H. Shin, W. Zhang, R. Wang and P. Rao, Water, Air, Soil Pollut., 2017, 228.

33 N. Tian, X. K. Tian, X. W. Liu, Z. X. Zhou, C. Yang, L. L. Ma, C. Tian, Y. Li and Y. X. Wang, Chem. Commun., 2016, 52, 11955-11958.

34 M. T. Rahman, T. Kameda, S. Kumagai and T. Yoshioka, React. Kinet., Mech. Catal., 2017, 120, 703-714.

35 L. J. Ma, S. M. Islam, H. Y. Liu, J. Zhao, G. B. Sun, H. F. Li, S. L. Ma and M. G. Kanatzidis, Chem. Mater., 2017, 29, 3274-3284.

36 P. Wu, J. S. Wu, L. Xia, Y. Liu, L. Y. Xu and S. X. Song, RSC Adv., 2017, 7, 26104-26112.

37 H. Lu, Z. Zhu, H. Zhang, J. Zhu, Y. Qiu, L. Zhu and S. Küppers, ACS Appl. Mater. Interfaces, 2016, 8, 2534325352.

38 H. Lu, Z. Zhu, H. Zhang, J. Zhu and Y. Qiu, Chem. Eng. J., 2015, 276, 365-375.

39 J. Hong, Z. Zhu, H. Lu and Y. Qiu, Chem. Eng. J., 2014, 252, 267-274.

40 J. Yu, Z. Zhu, H. Zhang, Y. Qiu and D. Yin, Environ. Sci. Pollut. Res., 2018, 24, 24293-24304.

41 V. Rives, Layered Double Hydroxides: Present and Future, Nova Science Publishers, Inc., New York, 2001.

42 W. Kagunya, R. Baddour-Hadjean, F. Kooli and W. Jones, Chem. Phys., 1998, 236, 225-234.

43 K. S. W. Sing and R. T. Williams, Adsorpt. Sci. Technol., 2004, 22, 773-782.

44 Y. Li, Y. Xu, X.-y. Chen, F. Ge and R.-l. Zhu, Appl. Catal., B, 2014, 160, 115-121.

45 I. Langmuir, J. Am. Chem. Soc., 1916, 38, 2221-2295.

46 I. Langmuir, J. Am. Chem. Soc., 1917, 39, 1848-1906.
47 H. Freundlich, Colloid and Capillary Chemistry, Methuen, London, 1926.

48 R. Sips, J. Chem. Phys., 1948, 16, 490-495.

49 S.-H. Lee, M. Tanaka, Y. Takahashi and K.-W. Kim, Chemosphere, 2018, 211, 903-911.

50 H. Lu, S. Liu, H. Zhang, Y. Qiu, J. Zhao and Z. Zhu, Water, 2018, 10, 1150.

51 S. V. Prasanna and P. V. Kamath, J. Colloid Interface Sci., 2009, 331, 439-445.

52 Y. S. Ho and G. McKay, Water Res., 2000, 34, 735-742.

53 A. Violante, M. Pucci, V. Cozzolino, J. Zhu and M. Pigna, J. Colloid Interface Sci., 2009, 333, 63-70.

54 A. G. Caporale, M. Pigna, J. J. Dynes, V. Cozzolino, J. Zhu and A. Violante, J. Hazard. Mater., 2011, 198, 291-298.

55 F. Kolbe, H. Weiss, P. Morgenstern, R. Wennrich, W. Lorenz, K. Schurk, H. Stanjek and B. Daus, J. Colloid Interface Sci., 2011, 357, 460-465.

56 K. H. Goh and T. T. Lim, J. Hazard. Mater., 2010, 180, 401408.

57 K. Yang, L.-g. Yan, Y.-m. Yang, S.-j. Yu, R.-r. Shan, H.-q. Yu, B.-c. Zhu and B. Du, Sep. Purif. Technol., 2014, 124, 36-42.

58 C. D. Wagner and G. E. Muilenberg, Handbook of X-ray Photoelectron Spectroscopy: A Reference Book of Standard Data for Use in X-ray Photoelectron Spectroscopy, Physical Electronics Division, Perkin-Elmer Corp., Eden Prairie, Minn., 1979.

59 D. Briggs, Handbook of X-ray and Ultraviolet Photoelectron Spectroscopy, Heyden, London, Philadelphia, 1977.

60 R. Jerome, P. Teyssie, J. J. Pireaux and J. J. Verbist, Appl. Surf. Sci., 1986, 27, 93-105.

61 C. D. Wagner, Faraday Discuss. Chem. Soc., 1975, 60, 291300.

62 D. E. Haycock, M. Kasrai, C. J. Nicholls and D. S. Urch, J. Chem. Soc., Dalton Trans., 1978, 1791-1796, DOI: 10.1039/ DT9780001791.

63 T. Birchall, J. A. Connor and L. H. Hillier, J. Chem. Soc., Dalton Trans., 1975, 2003-2006.

64 S. Hoste, D. F. Van De Vondel and G. P. Van Der Kelen, J. Electron Spectrosc. Relat. Phenom., 1979, 17, 191-195. 